\title{
Characterization of a novel human BFL-1-specific monoclonal antibody
}

\author{
Lahiru Gangoda ${ }^{1,2} \cdot$ Charis E. Teh $^{1,2} \cdot$ Michael A. Dengler ${ }^{1,2} \cdot$ Sarah A. Best $\mathbb{D}^{1,2} \cdot$ Clare E. Weeden $^{1,2} \cdot$ Lin Tai $^{1,2}$. \\ Erinna F. Lee ${ }^{3,4,5} \cdot$ Walter D. Fairlie ${ }^{3,4,5} \cdot$ Kate D. Sutherland $\mathbb{D}^{1,2} \cdot$ Leonard C. Harrison ${ }^{1,2}$ - Daniel H. Gray $\mathbb{D}^{1,2}$. \\ Andreas Strasser ${ }^{1,2} \cdot$ Marco J. Herold $\mathbb{D}^{1,2}$
}

Received: 26 September 2019 / Revised: 28 October 2019 / Accepted: 29 October 2019 / Published online: 12 November 2019

(c) The Author(s), under exclusive licence to ADMC Associazione Differenziamento e Morte Cellulare 2019

BFL-1 is the least studied pro-survival BCL-2 family member, partly due to the lack of high-quality tools, such as antibodies that can detect this protein at endogenous levels. $B F L-1$ mRNA expression may not mirror BFL-1 levels due to post-translational regulation of this protein $[1,2]$. Hence, there is a requirement for a reliable antibody to detect endogenous BFL-1 in cells.

To generate BFL-1-specific monoclonal antibodies, we utilized mice lacking A1 (the mouse homologue of BFL-1) $[3,4]$. We hypothesized that $A 1^{-1-}$ mice would generate a better immune response against BFL-1 as their immune cells have not been tolerized to the highly homologous mouse A1 protein. Hence, we immunised the mice with a truncated recombinant BFL-1 protein (aa1-151, lacking the $\mathrm{C}$ terminal region) and two KLH-conjugated peptides corresponding to the BFL-1 protein regions aa71-84 and aa129-154. One BFL-1 reactive monoclonal antibody identified in an ELISA screen (data not shown) was validated by Western blot analysis of lysates from

Supplementary information The online version of this article (https:// doi.org/10.1038/s41418-019-0454-y) contains supplementary material, which is available to authorized users.

Marco J. Herold

herold@wehi.edu.au

1 Walter and Eliza Hall Institute of Medical Research, 1G Royal Parade, Parkville, Melbourne, VIC 3052, Australia

2 Department of Medical Biology, University of Melbourne, Parkville, Melbourne, VIC 3010, Australia

3 La Trobe Institute for Molecular Science, La Trobe University, Melbourne, VIC 3086, Australia

4 Olivia Newton-John Cancer Research Institute, Heidelberg, VIC 3084, Australia

5 School of Cancer Medicine, La Trobe University, Melbourne, VIC 3086, Australia
HEK293T cells overexpressing FLAG-tagged BFL-1 protein [5] (Supplementary Fig. 1). To verify the specificity of the BFL-1 antibody, we examined BFL-1 protein stability in M14 (previously shown to express BFL-1 protein [6]) and SK-MEL30 melanoma cells. As expected, the protein synthesis inhibitor cyclohexamide (CHX) decreased and the proteasome inhibitor (MG132) increased the intensity of the BFL-1 protein band (Supplementary Fig. 2). To test the cross-reactivity of the BFL-1-specific antibody for its murine counterpart A1, lysates from LPS (known to upregulate $A l$ mRNA [7]) stimulated lung tissues were analysed by Western blotting. Lysates from BFL-1 CRISPR deleted [8] and parental M14 cells served as controls. This demonstrated the reactivity of the monoclonal antibody to human BFL-1 but not mouse A1 (Supplementary Fig. 3).

Importantly, the BFL-1 antibody could robustly be used for BFL-1 immunoprecipitation (Fig. 1a) and for immunofluorescence staining in M14 cells (Supplementary Fig. 4 and Fig. 1b). To validate the results in the immunofluorescence setting, $2 \mathrm{~h}$ treatment of M14 cells with CHX or MG132 decreased or slightly increased, respectively, the APC signal corresponding to the BFL-1 protein (Fig. 1b). Mitotracker Orange was added to the serum-free growth medium for $1 \mathrm{~h}$ before fixation, permeabilization, and antibody staining. Notably, the BFL-1 protein was predominantly present in the cytosol and did not co-localize with the mitochondrial staining, consistent with the reported sub-cellular localization of A1, its mouse homologue [1]. Unfortunately, the BFL-1 antibody did not yield reproducible results in flow cytometry experiments (data not shown).

To validate the applicability of the monoclonal BFL-1 antibody in primary human cells, peripheral blood mononuclear cells (PBMCs) were isolated from healthy donors, stimulated in culture for 3 days with antibodies against CD3 and CD28 (known to increase the A1 protein expression in mouse $\mathrm{T}$ cells $[4,9])$ and cell lysates subjected to Western 

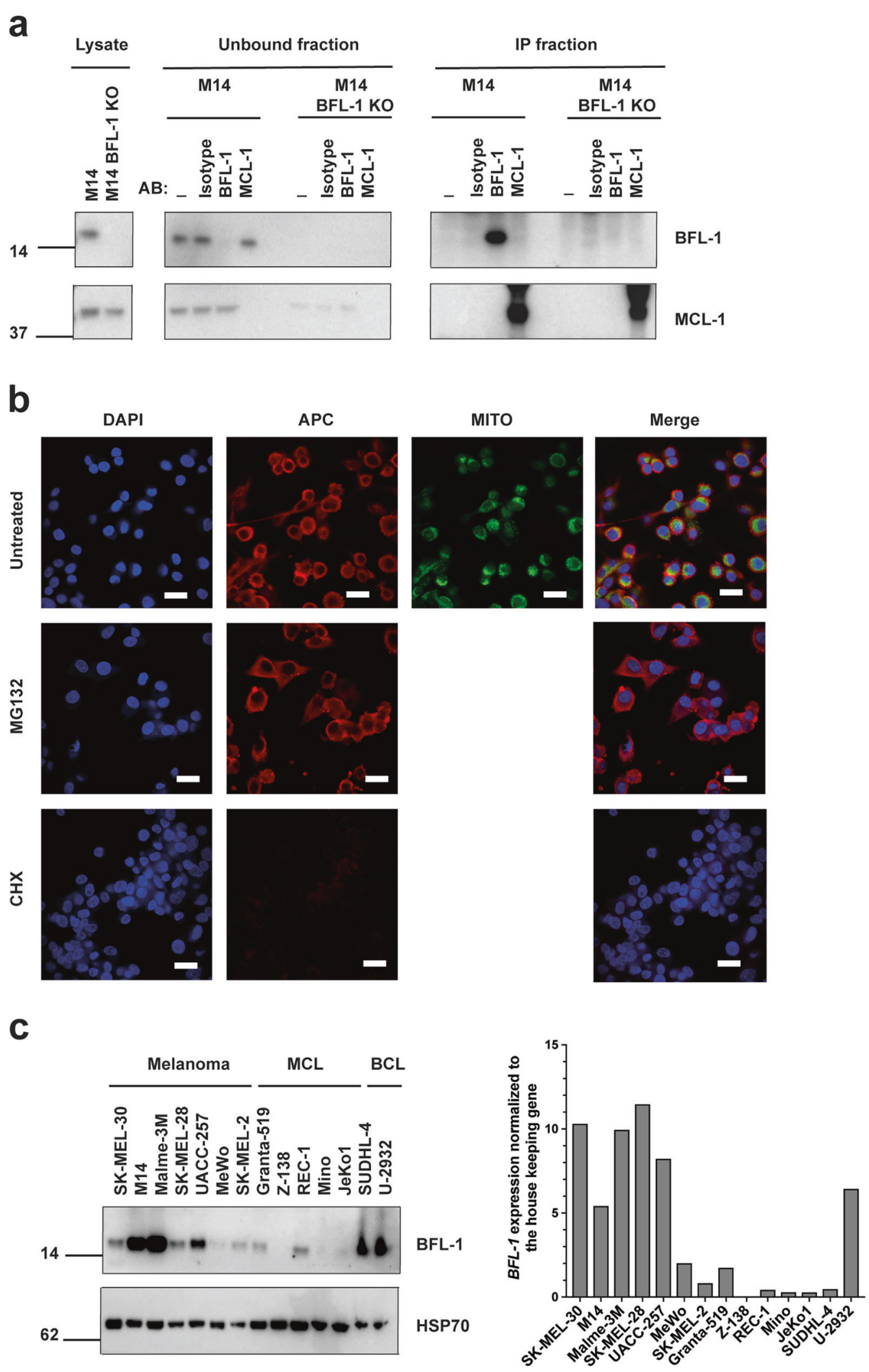

blot analysis. Importantly, we could detect a band corresponding to the correct molecular weight of BFL-1 in stimulated samples but not in the unstimulated cells

(Supplementary Fig. 5). To examine whether BFL-1 protein corresponds to BFL-1 mRNA expression, Western blot analysis and quantitative PCR analysis were performed 
Fig. 1 A novel BFL-1 specific monoclonal antibody reliably detects this pro-survival BCL-2 family member, even at endogenous levels. a For immunoprecipitation experiments, pre-cleared melanoma cell (M14 and M14 BFL-1 KO) lysates were incubated overnight with BFL-1 antibody or an Ig isotype-matched control antibody $(\operatorname{IgG} 2 \mathrm{a} / \mathrm{\kappa})$ and protein G-sepharose beads. Immunoprecipitation of MCL-1 was performed with a previously characterized MCL-1-specific monoclonal antibody (19C4-15 clone [10]) as a positive control for the immunoprecipitation protocol. The immunoprecipitated proteins were then subjected to electrophoresis and Western blotting. b M14 melanoma cells grown overnight on coverslips were treated for $2 \mathrm{~h}$ with cycloheximide or MG132 and stained with the primary antibody (antiBFL-1 or Ig isotype matched control antibody at $25 \mu \mathrm{g} / \mathrm{mL}$ ) and subsequently with anti-mouse IgG specific secondary antibodies conjugated to APC (red). Nuclei were stained with DAPI (blue) and slides mounted for confocal imaging. Mitotracker Orange was added to cells prior to fixation to stain for mitochondria. Scale bars indicate $20 \mu \mathrm{m}$. c The monoclonal antibody against BFL-1 detects BFL-1 at endogenous levels in a panel of human melanoma, mantle cell (MCL) and other B cell lymphoma (BCL) derived cell lines by Western blotting. Probing for HSP70 served as a protein loading control (left side). Total RNA was extracted from the same cell lines and converted to cDNA. RTPCR analysis was performed using Taqman probe sets for the housekeeping gene $H M B S$ and $B F L-1$ with relative quantification applied using the $\Delta \mathrm{Ct}$ method (right side)

side-by-side on a human cell line panel (Fig. 1c). Since BFL-1 protein is regulated by ubiquitin-dependent proteasomal degradation [1], $B F L-1$ mRNA expression data failed to fully reflect BFL-1 protein expression. The discrepancy between transcription and protein levels of BFL-1 emphasizes the importance of having a reliable BFL-1 specific antibody. Collectively, our studies describe a robust human BFL-1-specific monoclonal antibody capable of reliably detecting endogenous BFL-1 protein in cell lines and primary human cells. This antibody will enable further studies into the regulation of BFL-1 protein in homeostasis and disease.

Acknowledgements We thank Dan Fayle, Krystal Hughes and Giovanni Siciliano for expert animal care. This work was supported by grants and fellowships from the Australian National Health and Medical Research Council (NHMRC) (Project Grants 1145728 to MJH, 1143105 to MJH and AS, 1122783 to APN, Program Grants 1016701 to AS and Fellowships 1020363 to AS, 1156095 to MJH) the Leukemia and Lymphoma Society of America (LLS SCOR 7001-13 to AS and MJH), the Cancer Council of Victoria (project grant 1052309 to AS and Venture Grant to MJH and AS) as well as by operational infrastructure grants through the Australian Government Independent
Research Institute Infrastructure Support Scheme (361646 and 9000220) and the Victorian State Government Operational Infrastructure Support Program.

\section{Compliance with ethical standards}

Conflict of interest The authors declare that they have no conflict of interest.

Publisher's note Springer Nature remains neutral with regard to jurisdictional claims in published maps and institutional affiliations.

\section{References}

1. Herold MJ, Zeitz J, Pelzer C, Kraus C, Peters A, Wohlleben G, et al. The stability and anti-apoptotic function of A1 are controlled by its C terminus. J Biol Chem. 2006;281:13663-71.

2. Kucharczak JF, Simmons MJ, Duckett CS, Gelinas C. Constitutive proteasome-mediated turnover of $\mathrm{Bfl}-1 / \mathrm{A} 1$ and its processing in response to TNF receptor activation in FL5.12 pro-B cells convert it into a prodeath factor. Cell Death Differ. 2005;12: 1225-39.

3. Schenk RL, Tuzlak S, Carrington EM, Zhan Y, Heinzel S, Teh $\mathrm{CE}$, et al. Characterisation of mice lacking all functional isoforms of the pro-survival BCL-2 family member A1 reveals minor defects in the haematopoietic compartment. Cell Death Differ. 2017;24:534-45.

4. Tuzlak S, Schenk RL, Vasanthakumar A, Preston SP, Haschka $\mathrm{MD}$, Zotos D, et al. The BCL-2 pro-survival protein A1 is dispensable for $\mathrm{T}$ cell homeostasis on viral infection. Cell Death Differ. 2017;24:523-33.

5. Lang MJ, Brennan MS, O'Reilly LA, Ottina E, Czabotar PE, Whitlock E, et al. Characterisation of a novel A1-specific monoclonal antibody. Cell Death Dis. 2014;5:e1553.

6. Lee EF, Harris TJ, Tran S, Evangelista M, Arulananda S, John T, et al. BCL-XL and MCL-1 are the key BCL-2 family proteins in melanoma cell survival. Cell Death Dis. 2019;10:342.

7. Ottina E, Tischner D, Herold MJ, Villunger A. A1/Bfl-1 in leukocyte development and cell death. Exp Cell Res. 2012;318: 1291-303.

8. Kotschy A, Szlavik Z, Murray J, Davidson J, Maragno AL, Le Toumelin-Braizat G, et al. The MCL1 inhibitor S63845 is tolerable and effective in diverse cancer models. Nature. 2016;538:477-82.

9. Koenen P, Heinzel S, Carrington EM, Happo L, Alexander WS, Zhang JG, et al. Mutually exclusive regulation of $\mathrm{T}$ cell survival by IL-7R and antigen receptor-induced signals. Nat Commun. 2013;4:1735.

10. Mason KD, Vandenberg CJ, Scott CL, Wei AH, Cory S, Huang DC, et al. In vivo efficacy of the Bcl-2 antagonist ABT-737 against aggressive Myc-driven lymphomas. Proc Natl Acad Sci USA. 2008;105:17961-6. 